Germán Hidalgo

\section{Los ecos de la planta Organización lógica de las sensaciones espaciales ${ }^{1}$}

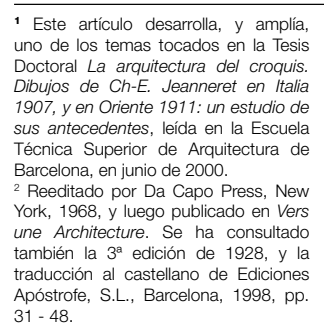

Apóstrofe, S.L., Barcelona, 1998, pp.
Las reflexiones de Le Corbusier sobre la planta como herramienta estructural, generadora y reguladora del proyecto arquitectónico, tienen un curioso punto de partida en las axonometrías publicadas por Choisy. La visión de la arquitectura como una disciplina severa y precisa, más cerca de la ingeniería que del arte, emparenta estas representaciones que revelan a la mirada un orden abstracto de partes, sistemas y relaciones.

Palabras clave: Arquitectura - representación, teoría de la arquitectura, plantas de arquitectura, Le Corbusier, Choisy, Acrópolis.

Le Corbusier's reflections on the plan view as a structural element that generates and regulates the architectural project have a curious starting point in the axonometrics published by Choisy. The vision of architecture as a severe and precise discipline, closer to engineering than to art, brings together these representations that reveal to the ey an abstract ordering of parts, systems and relations Key words: Architecture - representation, theory of architecture, plan views, Le Corbusier, Choisy, Acropolis.
I Al inicio de la década del veinte del siglo pasado, como es bien sabido, comienzan a cristalizar en la mente de Charles Edouard Jeanneret, Le Corbusier, las imágenes y las ideas de una nueva arquitectura. Una arquitectura diferente que, para el joven arquitecto de La Chaux-deFonds, sólo revela sus secretos a través de la representación en planta.

Quizás, donde mejor podemos ver expuestos los argumentos que avalan esta proposición es en un artículo que publica en L'Esprit Nouveau, bajo la rúbrica de Le Corbusier-Saugnier, cuyo título es: "Trois rappels à MM. les architectes. 3e Article. Le Plan" (Le Corbusier-Saugnier, 1920), y que posteriormente incluirá en Vers une Architecture ${ }^{2}$. Evidentemente, no queremos detenernos aquí en la mera revisión de los argumentos expuestos, sino muy por el contrario proyectarnos en los alcances e implicancias que, en el ámbito de la representación, ellos adquieren.

Revisar el contenido escrito e ilustrado del artículo en cuestión nos permite, sucintamente, remontar las aguas que condujeron a Le Corbusier desde las fuentes del racionalismo estructural francés hasta el purismo de los años veinte. En efecto, en ese artículo se nos invita en primer lugar a considerar la planta (le plan) como
3 Esta imagen, que corresponde a la villa La Roche-Jeanneret, sólo aparece Architecture, aquélla de 1928, p. 48. ${ }_{4}$ El protagonismo del ingeniero los albores del siglo XX fue analizado por Juan José Lahuerta a la luz de la literatura de Julio Verne. En nota aparte senala due tema de los ingenieros en Verne en relación con la discusión artística y arquitectónica de los primeros años del siglo" se encontro en otro texto de Reyner Banham.

Al final del artículo Le Corbusier nos informa sobre la fuente de estas edición de 1943.
En la nota que abre la Histoire de Architecture, Choisy explica el modo gráficos: "Les documents graphiques quelquefois simplifiés par la suppression de détails superflys sont, pour le plus grand nombre, présentés en projection axonométrique, système qui a la clarté de la perspective et se prête à des mesures seule image mouvementée et animée comme l'edifice lui-même, tient lieu de la figuration abstraite, fractionnée par plan, coupe et élévation. Le lecteur a sous les yeux, à la fois, le plan, l'exterieur de l'édifice, sa coupe et ses dispositions
intérieures. TOUTES CES FIGURES SONTACCOMPAGNEES D'ÉCHELI"

la gran instancia que permite la organización de la forma arquitectónica y urbana. En segundo lugar, y una vez establecido este supuesto, a dar una mirada a la ciudad industrial de Tony Garnier, como asimismo, a la idea de "ciudadestorres" elaborada por Auguste Perret para, finalmente, concluir con algunas de las propias creaciones del articulista: el proyecto para una ciudad contemporánea, y la imagen del techo jardín de una de sus villas de París ${ }^{3}$.

Pero, veamos cuáles son esos argumentos que hacen posible situar la planta en tan preeminente condición, y que autorizan a que nuestro autor sentencie: Le plan est le générateur.

Partamos por lo elemental. Para Le Corbusier, una planta de arquitectura debe contener mucha más información que la aparentemente necesaria para establecer la distribución de los recintos de un edificio: para él, le plan est la détermination du tout; il est le moment décisif (Le CorbusierSaugnier, 1920).

En efecto, en esta frase se nos indica que el trazado de la planta debe representar la "totalidad" de la información que define cómo es un edificio, considerando sus espacios, sus volúmenes, su materia, su estructura; en resumen, todo.

"Toda la estructura se eleva desde la base y se desarrolla
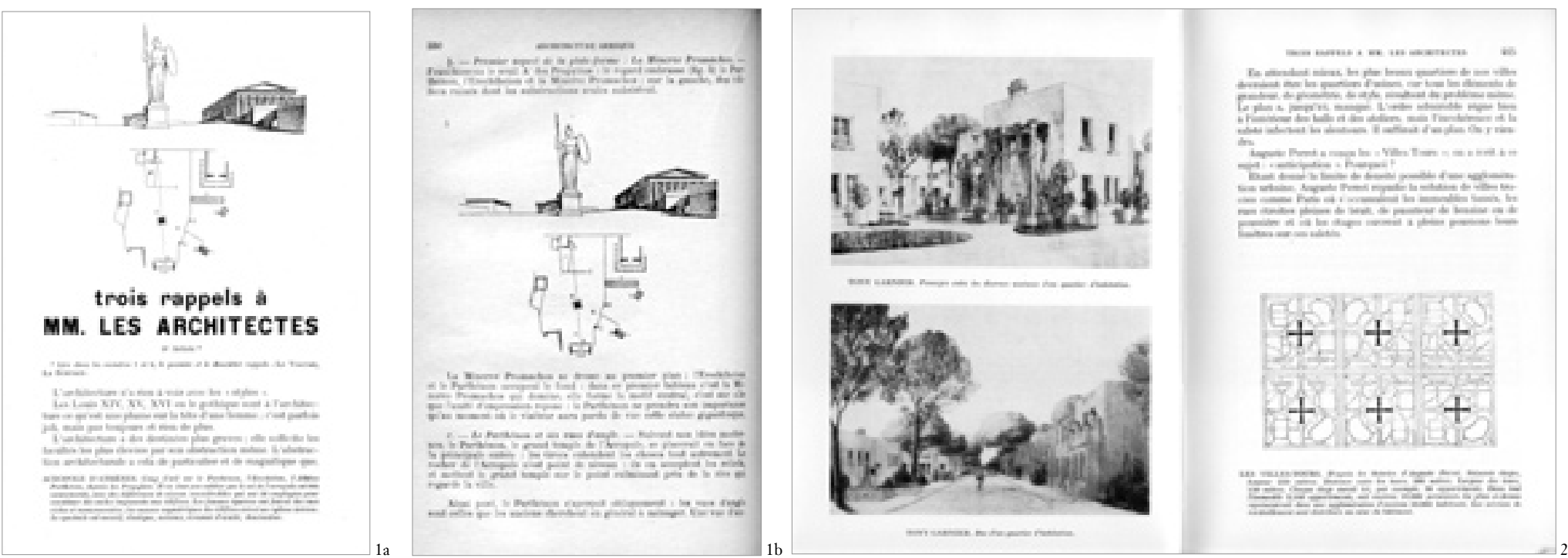
1a Portada del artículo publicado por Le Corbusier en L'Esprit Nouveau $\mathrm{N}^{\circ} 4,192$

1b Dibujo de la Atenea Prómacos publicado por Choisy

2 Las propuestas urbanas de Tony Garnier y las ciudades-torres" basadas e Publicadas en L'Esprit Nouveau
3 Axonometría de la basílica de Santa Sofía, proveniente del libro de Choisy, publicada en L'Esprit Nouveau

4 Planta y paisaje. La planta "aparentemente desordenada" de la Acrópolis, publicada en L'Esprit Nouveau

5 La planta de la Acrópolis como un paisaje donde sólo las masas están equilibradas. Publicada por Choisy siguiendo una regla que está escrita en la base de la planta". Ella, sintetizando el cúmulo de datos y decisiones que le han permitido adquirir forma, y en su nivel de comprensión más elevado, debe transmitir y hacer comprensible una profunda sensación de armonía; la propia que distingue a la arquitectura, y que consiste en un ritmo que se desarrolla en las tres dimensiones del espacio, y que involucra desde el más sencillo al más sofisticado de sus elementos; todo bajo el control de una única ley que los define y determina. En virtud de esto, allí también dirá: “...una planta no es tan lindo de trazar como el rostro de una madona; es una abstracción austera, una algebrización árida a la vista". Trazar una planta, por tanto, exigirá una disciplina severa, será un gran esfuerzo intelectual destinado a generar un gozo sensorial y del espíritu. La planta, recordémoslo, es el générateur, y en consecuencia debe llevar en sí, l'essence de la sensation.

$\mathrm{Y}$ en ese mundo que Le Corbusier entrevé, que se le aproxima recién iniciado el siglo XX, solicita una actualización del sentido de la planta (del plan). En el mundo de la estadística y del cálculo (de la abstracción y la mercancía), la planta es la representación que mejor encarna estos nuevos valores emergentes. Ciertamente, para el Le Corbusier de los años veinte, la planta será le clé de cette évolution.
II Esta primera revisión despeja todo tipo de dudas con respecto a la posición ideológica que articula el pensamiento expuesto en el escrito: la planta es la auténtica expresión del necesario trasfondo racional que debe sustentar los principios de la nueva arquitectura. Por cierto, una posición muy en sintonía con uno de los tópicos que por entonces preocupaba a nuestro autor, y que queda en evidencia en el enunciado de otro de sus artículos: "Estética del ingeniero, Arquitectura" (Le Corbusier-Saugnier, 1920) ${ }^{4}$.

De acuerdo a estos antecedentes, no debiera sorprendernos la fuente que utiliza Le Corbusier para ilustrar su particular concepto de planta: la Histoire de l'Architecture de Auguste Choisy (1841-1908) $)^{5}$, una obra que examina la disciplina arquitectónica a la luz de sus sistemas constructivos y técnicos. Sin embargo, y esto sí se puede considerar un motivo de sorpresa, advertiremos que entre las imágenes seleccionadas lo que encontraremos, mayoritariamente, no serán plantas, sino un tipo muy especial de representaciones: axonometrías.

III Con seguridad Auguste Choisy, ingeniero, militar y gran estudioso de la historia de la arquitectura, atento a las cualidades prácticas de la axonometría -quizás el sistema de representación menos utilizado por los proyectistas- la rescata desde el parcial olvido en que se encontraba y la hace actuar de manera protagónica en su tratado ${ }^{6}$. Muchas de las axonometrías que allí nos presenta, especialmente las seccionadas y miradas desde abajo, más que representaciones de obras de arquitectura parecen referir la forma precisa y esencial de una pieza mecánica. En efecto, advertimos que al dibujarlas se ha querido resaltar sus dimensiones, las conexiones que permiten su unión al resto del sistema al que pertenecen, o señalar la distribución de la materia que las constituye.

Choisy intentando ser directo, escueto, e incluso didáctico en la comunicación de sus argumentos, trasladó al terreno de la arquitectura un sistema de representación que era parte de su propio campo disciplinar, la ingeniería y la logística militar, justamente para poner en valor aquellos aspectos de la arquitectura que tienen relación con su organización física, su estabilidad y materialidad; en definitiva, para valorizar y mirar con nuevos ojos una concreta idea de orden. Como muy bien apuntó Reyner Banham, con esta novedosa estrategia para representar los edificios Choisy logró reducir la arquitectura a pura abstracción, revelando de este modo el orden subyacente que gobernaba a las obras
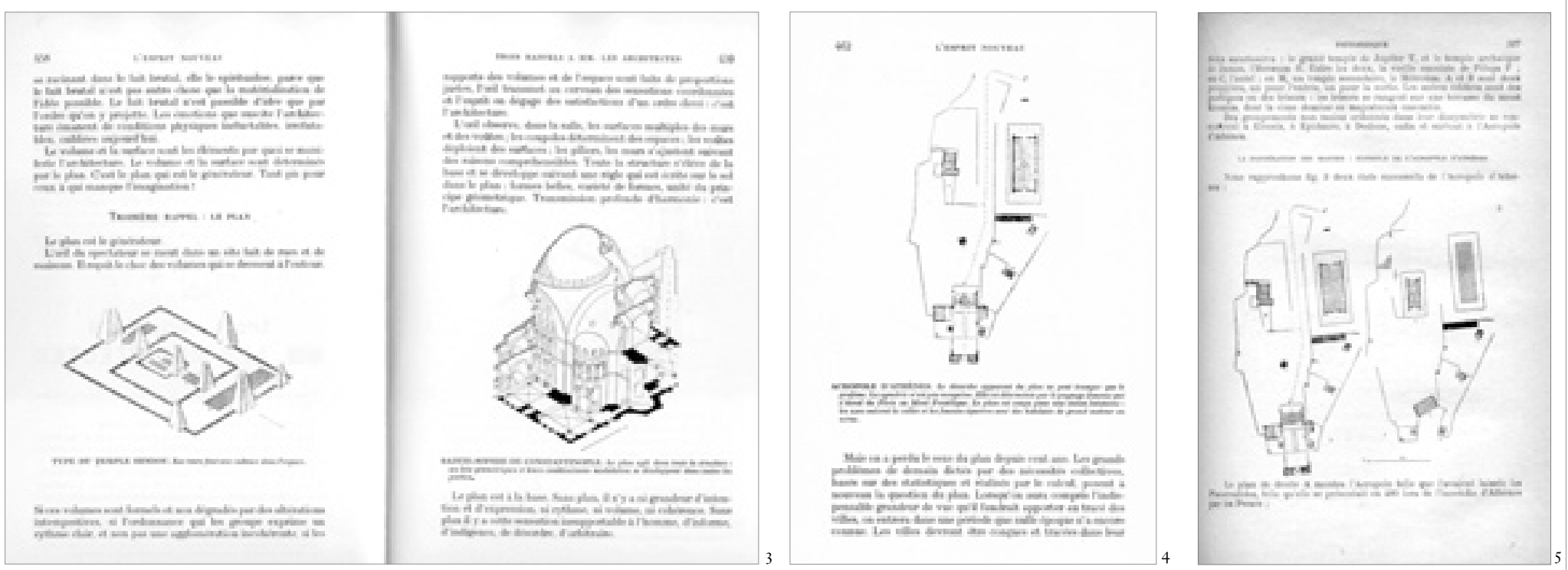
7 "Fue esta cualidad abstracta, esta construcción lógica que superaba el elegante dibui aspecto exterior, sobre la página, lo que atrajo hacia esas ilustraciones a la generación nacida en las decadas de 1880 y18 a la consolidacion del arte abstracto. y utiliźó muchas de ellas hizo suyas Nouveau, a través del cual cobraron nueva vida y más amplia circulación". Este párrafo ha sido igualmente citado por Frampton. representadas, y en consecuencia hacer explícitos aspectos insustituibles para su total comprensión (Banham, 1960) ${ }^{7}$.

IV Es comprensible, por tanto, la elección de Jeanneret; yla utilización que hizo de las axonometrías del libro de Choisy. En todos los ejemplos que tomó, encontramos la voluntad de referir una concreta idea de orden, ya sea jerarquizando o clasificando sus partes; aspectos sólo visibles desde este singular, y revelador, punto de vista.

Sin embargo, Jeanneret se da una licencia: llegada la hora de referir el sabio orden que gobierna la Acrópolis de Atenas, del texto de Choisy no elige una axonometría, sino dos plantas. Es así como una de ellas queda integrada en la secuencia de axonometrías ya descrita, mientras que la segunda la utiliza como portada del artículo. Esta última, como ya veremos, va acompañada de una perspectiva cónica.

Revisemos, pues, los argumentos que hicieron posible esta clara elección. En la planta que Le Corbusier utilizó como portada ${ }^{8}$, Choisy había querido evidenciar la presencia de un eje que nace desde los Propileos y que va a morir en uno de los vértices del Erecteion, atravesando en su camino la protagónica estatua de Atenea Prómacos (Choisy, 1899).

La idea parece clara, tanto en uno como en otro autor. Choisy refiere con ese eje aquello que considera lo pittoresque de la Acrópolis, es decir, una suerte de "desorden" propio del paisaje natural, que en la Acrópolis queda evidenciado, precisamente, en la libertad con que los volúmenes principales de la meseta se disponen con respecto a él. Evidentemente, aquí se quiere hacer presente la idea de una silenciosa armonización de masas y vacíos, entre volúmenes y espacios.

El desafío se ha vuelto evidente: advertimos que para hacer explícita esta armonización, que quiere mostrarse natural y espontánea, Choisy se ve en la necesidad de complementar su representación, agregando a la planta de la Acrópolis la perspectiva cónica que hemos anticipado. Siendo consecuente con su espíritu didáctico, Choisy nos saca de la bidimensionalidad del plano, y nos sitúa en el vértice de la pirámide visual, de pie, caminando a partir del arranque de ese eje principal, para desde allí contemplar el "verdadero" orden que vincula a los templos. Un orden que, años después, ya será familiar para Le Corbusier-Saugnier, y del cual nos advierte cuando escribe a los pies de la otra planta: "El desorden aparente de la planta -de la Acrópolis- sólo engaña al profano" .

Ya estamos en condiciones de llegar a una primera conclusión cierta: más allá de ser un instrumento

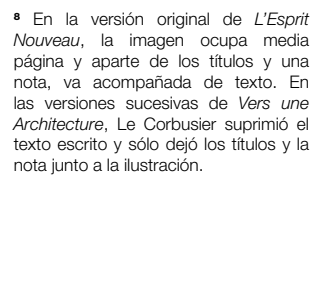

"Le désordre apparent du plan ne peut tromper que le profane. La symétrie n'es paysage fameux qui s'étend du du Pirée au Mont Pentélique. Le plan est conçu pour une vision lointaine: les axes suivent la vallee et les fausses equerres sont des "Trois re grand metteur en scene".

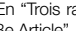

de descripción, la planta -de la Acrópolis-deviene en instancia que cifra un secreto bien guardado, o en palabras de Le Corbusier: la planta es la determinación de tout. Mientras, la perspectiva está allí para recordarnos que ese secreto sólo se revelará a quienes saben observar: es decir, ver, traspasar con la mirada la realidad aparente.

V Llegados a este punto, podemos advertir que el examen al cual hemos sometido las imágenes del artículo nos ha permitido reflexionar sobre el modo de representar una ordenación arquitectónica particular, de extremada y acabada síntesis. El recurso de la planta, que según Jeanneret es "иna austera abstracción, una algebrización árida a la vista", que "lleva en sí la esencia misma de la sensación", aún con todo su poder evocador, pareciera mostrarse limitado para una cabal representación.

Un dato clave para penetrar en el núcleo de este problema lo podemos encontrar si continuamos la lectura de la sentencia de Le Corbusier que hemos venido comentando:

"El desorden aparente de la planta sólo engaña al profano. El equilibrio no es mezquino. Está determinado por el famoso paisaje que se extiende desde el Pireo al Monte Pentélico. El plan está concebido para una visión lejana!".

Ciertamente, tanto Choisy como Le Corbusier eran conscientes del importante rol que jugaba el paisaje en la organización de aquel plan, y en consecuencia, del sentido que adquiría el tomar una prudente distancia para su observación.

Choisy señalaba en su tratado que los griegos, más allá de respetar la naturaleza del lugar en que situaban sus templos, los construían deliberadamente en aquéllos que presentaban un singular carácter geográfico; de modo que, con su implantación, contribuían a realzar y potenciar esa clara identidad. Precisamente, hablamos de aquellas mismas condiciones de implantación en el paisaje que había observado Le Corbusier en su visita a Atenas de 1911, y que le había permitido referirse a la inserción del Partenón en el paisaje, como si fuera una perla en su valva (Jeanneret, 1966).

VI Sobre esta cuestión, una observación esclarecedora es la que aporta el historiador Leonardo Benevolo, en el contexto de la perspectiva renacentista (Benevolo, 1991). Allí refiere el principio visual que gobernaba la organización de las "más grandes sistematizaciones artificiales" del mundo antiguo, incluyendo entre ellas a la Acrópolis de Atenas.

Según Benevolo, la visión tridimensional adecuada para percibir las obras monumentales funciona en un rango cuyo umbral máximo bordea los 300 metros; dentro de este rango las formas mantienen intacta a los ojos del espectador su condición volumétrica; mas, si nos situamos más allá de este límite, “...los objetos arquitectónicos devienen imágenes planas, caracterizadas por su cualidad cromática, incorporándose en la continuidad del fondo paisajístico...” (Benevolo, 1991). Una observación que claramente respalda, y entrega argumentos, al escueto párrafo escrito por Le Corbusier: "El plan -de la Acrópolis de Atenasestá concebido para una visión lejana".

Pero además Benevolo nos entrega nuevas y reveladoras ideas para la comprensión de este problema. Cuando se les observa desde una prudente distancia, los grandes conjuntos arquitectónicos se funden con el paisaje que les sirve de marco; al mirarlos así, desde la lejanía, se hace posible visualizar la verdadera ordenación que los articula; justamente, aquélla de la cual la planta es síntesis.

Planta, por tanto, que procura el orden, pero incapaz de revelarlo (del todo).

Entonces, pues, visto desde la lejanía, el conjunto arquitectónico se reduce a dos elementos fundamentales: su silueta y sus cualidades cromáticas, considerando que estas últimas variarán sustancialmente de acuerdo a las condiciones atmosféricas y de iluminación. Y reducción de un objeto a sus cualidades fundamentales qué es, sino aquello que entendemos por abstracción: voluntad de selección a partir de lo visible. En nuestro caso, figura que, aunque observada bajo los principios de la visión, queda reducida a imagen plana; perfil y color: reducción esencial que deja en evidencia los aspectos principales de su ordenación.

Éste es el argumento de fondo que propone Le Corbusier cuando escribe bajo la planta de la Acrópolis: "El plan está concebido para una visión lejana"; o lo que es lo mismo: la ordenación de la planta de la Acrópolis sólo puede ser visualizada (comprendida) cuando se la observa desde la lejanía.

VII Precisamente, la misma actitud con la que había enfrentado, diez años antes, al vigía de mármol: el Partenón, cuando lo dibujó desde el monte Lycabette, a un kilómetro de distancia. En efecto, en 1911, cuando logra por fin acometer lo que consideraba la mayor obra de arquitectura de todos los tiempos, como hemos visto, ya había leído la Histoire de Choisy; ya había comprendido el sentido profundo que se arraigaba en sus axonometrías, y había reparado al leer sus páginas que los antiguos griegos construían sus templos tratándolos como un paisaje donde sólo las masas están equilibradas. En otras palabras, conocía de antemano algunas de 


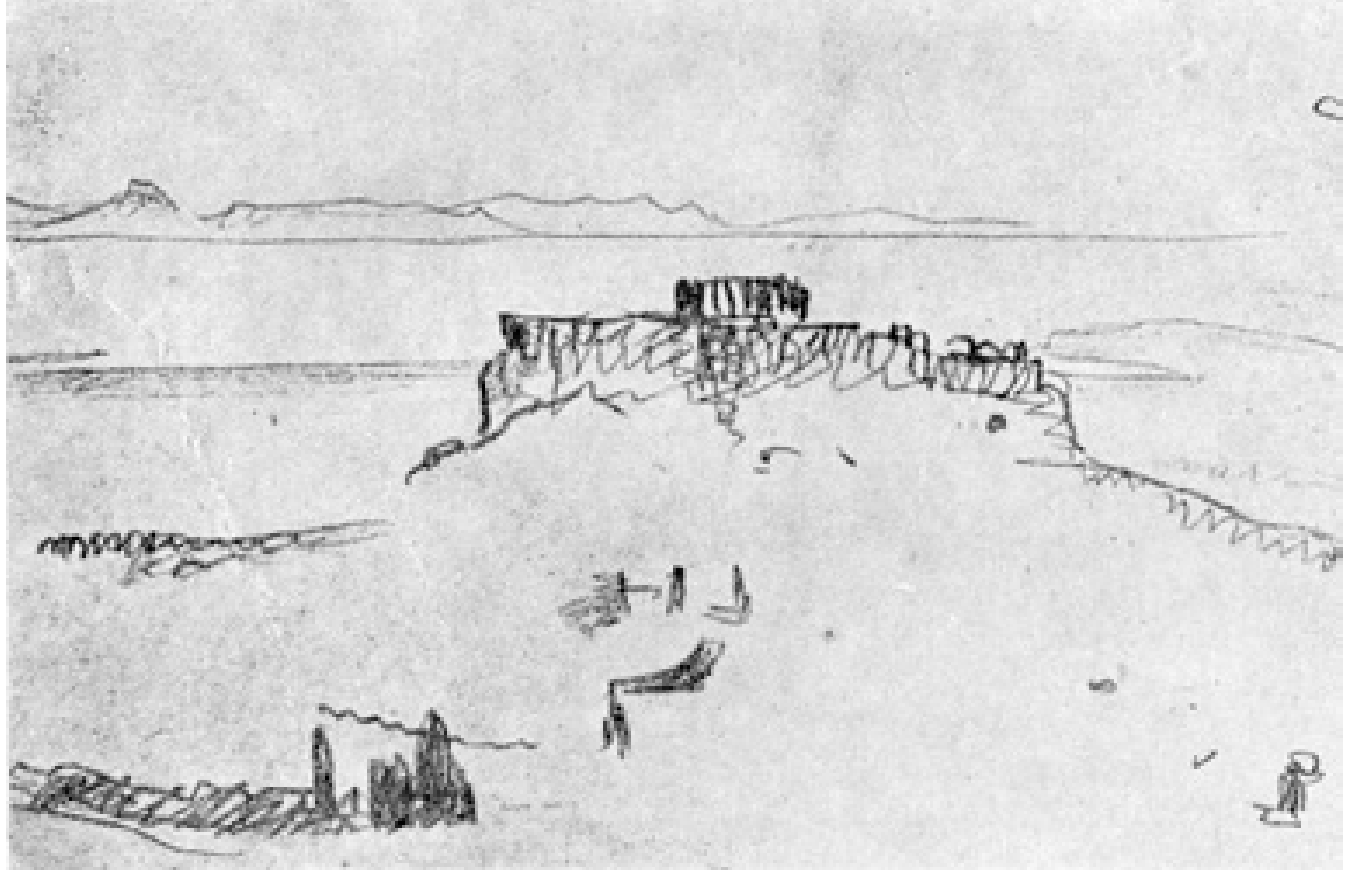

las claves para extraer los secretos de la Acrópolis y de su Partenón; para que sus ruinas, como tanto anhelaba, le supieran responder.

$\mathrm{Y}$, conocía también, después de haber hojeado su guía de viaje Baedeker, mucho antes de iniciar su viaje, desde qué lugar de Atenas podría contemplar semejante espectáculo, pues en una de sus láminas desplegables, pudo advertir la magnitud de ese gran panorama, Pris du Mont Lycabette. Una imagen potente que le quedó grabada, y que debía constatar, para dejarla como testimonio de los conocimientos adquiridos recientemente; dibujándola de acuerdo a los nuevos recursos gráficos que había incorporado, después de haber estudiado a Cèzanne, Signan, y Adolphe Appia, entre otros. Es decir, después de haber tomado contacto con los artistas clave de su tiempo, que actuaban como verdaderas puntas de lanza en la arremetida del arte moderno, encaminándolo hacia el territorio de la abstracción. Con sus croquis de la Acrópolis de 1911, Le Corbusier proponía "relegar" al infinito el vértice de la pirámide visual, propio de la perspectiva renacentista; una actitud que anticipaba en más de una década la ambición de orden equivalente planteada por El Lissitzky, en representación del movimiento suprematista (El Lissitzky, 1925). Tras esta voluntad visualizadora, sin duda, yacía el deseo de hacer audibles aquellos ecos que, desde la lejanía, emitía, como una voz que surgía desde el fondo de la tierra, el orden cifrado en la planta de la Acrópolis de Atenas.

Y era también el deseo de volver análogas dos formas de representación en apariencia diferentes, pero hermanadas en su aspiración de ser síntesis y expresión de esencialidad: la planta, por un lado, como visualización que se objetiva en el expediente de las proyecciones paralelas y en el consecuente mantenimiento de la proporcionalidad dimensional; y el croquis que, realizado desde la lejanía, era capaz de emular y superar la capacidad reveladora de dicha proyección geométrica al situar ese punto privilegiado que la perspectiva otorga allí donde, siguiendo a Euclides, sólo dos rectas paralelas pueden encontrarse. ARQ
Bibliografía Banham, Reyner; Theory and Design in the First Macbine Age. The Architectural Press, 1960. Traducción al castellano: Ed. Nueva Visión, Buenos Aires, 1977, pp. 39, 118-120. / Benevolo, Leonardo; La cattura dellinfinito. Laterza, Roma, 1991, pp. 16 y ss. / Choisy, Auguste; Histoire de l'Architecture. Ed. Baranger, París, 1899, p. 330. / Frampton, Kenneth; Modern Architecture: A Critical History. Thames and Hudson, Londres, 1980. Traducción al castellano: Editorial Gustavo Gili, Barcelona, 1996, p. 18. / Jeanneret, Charles Edouard; Le Voyage d'Orient. Éditions Forces Vives, 1966. Traducción al castellano: Colegio Oficial de Aparejadores y Arquitectos Técnicos, Murcia, 1993, pp. 169-170. / Lahuerta, Juan José; 1927. La abstracción necesaria en el arte y la arquitectura europeos de entreguerras. Ed. Anthropos, Barcelona, 1989, pp. 55 y ss. / Le Corbusier; Vers une Architecture. Les Éditions G. Crès et Cie., París, 1923. / Le Corbusier-Saugnier; "Trois rappels à MM. les architectes. 3e Article". En L'Esprit Nouveau $\mathrm{N}^{\circ} 4$, París, noviembre de 1920, pp. 457-470, 1.328-1.335./ Lissitzky, El; "A y Pangeometría”. En Europa Almanach, 1925. Traducción al castellano: Cátedra de Historia II, ETSAB, Apuntes $\mathrm{n}^{\circ}$ 2. Traducción al inglés: Lissitzky, El; Russia: An Architecture for World Revolution. Lund Humphries, Londres, 1970, pp. 142 a 149. 